\title{
The Impact of ART Initiation on Household Food Security Over Time
}

Bryan N. Patenaude ${ }^{\mathrm{a}, *}$

Natsayi Chimbindi ${ }^{b}$

Deenan Pillay b,c

Till Bärnighausen ${ }^{\mathrm{a}, \mathrm{b}, \mathrm{d}}$

aHarvard T.H. Chan School of Public Health, Department of Global Health \& Population, 665 Huntington Avenue, Building 1, room 1104, 02115, 1167 Boylston St., Apt. 12, Boston, MA, USA

${ }^{\mathbf{b}}$ Africa Health Research Institute, KwaZulu-Natal, South Africa

${ }^{c}$ University College London, Division of Infection \& Immunity, Cruciform Building, 90 Gower Street, London WC1E 6BT, UK

${ }^{\mathrm{d} H e i d e l b e r g}$ University Institute for Public Health, Im Neuenheimer Feld 130.3, Heidelberg 69120,

Germany

*Corresponding author. 


\begin{abstract}
While evidence suggests that adequate nutrition contributes to the efficacy of ART, the potential causal impact of ART initiation on household food security has not been thoroughly examined. In this study, we present some of the first causal evidence of the impact of ART initiation on household food security. We employ a quasi-experimental design, regression discontinuity, over 5540 individuals from an ongoing population cohort study in KwaZulu-Natal, South Africa, by utilizing the CD4 count-based ART eligibility threshold to examine the impact of ART initiation on household food security. We find that ART initiation causes a significant increase in the probability of food insecurity in the first year, which diminishes to zero within three years of initiation. Within the first year, ART initiation was found to significantly increase the probabilities that (1) the surveyed adult had missed any food in the past month by 10.2 percentage points $($ coefficient $=0.102,95 \% \mathrm{CI}=[0.039,0.166]) ;(2)$ any adult in the household had missed a meal in the past month by 15.2 percentage points $($ coefficient $=0.152,95 \% \mathrm{CI}=[0.073,0.231])$; and (3) any child in the household had missed a meal in the past month by 8.9 percentage points (coefficient $=0.0898,95 \% \mathrm{CI}=[0.0317,0.148])$. While we cannot definitively isolate the mechanistic pathways from ART to household food security, our results are consistent with ART affecting food security through household resource strain and patient appetite recovery. Several policies could mitigate the negative impact of ART on food security, in particular food parcels or food vouchers for ART patients in the first two years after treatment initiation.
\end{abstract}

\title{
Keywords:
}

HIV/AIDS; food security; regression discontinuity; quasi-experiment; econometric methods; household welfare; antiretroviral therapy; causal inference 


\section{Introduction}

Food security, broadly defined as "at all times having physical and economic access to sufficient, safe and nutritious food to meet di3etary needs and food preferences for an active and healthy life", is one of the most fundamental aspirations of impoverished households and an important component of the United Nation's Sustainable Development Goals. ${ }^{1,2}$ In addition to being a component of sustainable development, food security often interacts directly with other aspects of economic and human development including labor provision, educational attainment, and health. ${ }^{2}$ Food security also has particular relevance for regions facing the dual burden of persistent poverty and prevalent HIV. While antiretroviral therapy (ART) has been key in reducing the health burden of HIV through reducing morbidity and premature mortality as a result of HIV infection, its interaction with other components of sustainable development is uncertain., ${ }^{1,3}$ Given that there are many plausible pathways connecting ART and the sustainable development goals, such as food security, it is important to empirically test and quantify these relationships.

Numerous studies have shown the positive impact of ART on health, future wages, employment, education, and productivity. $3,4,5,6,7,8,9,10,11,12,13$ Despite these positive results, there are other plausible mechanisms from ART to household welfare, and the direction of net effects is unclear. On the one hand, patients often incur substantial costs when utilizing ART (e.g., for travel to and from health facilities); on the other hand, patients recover health and employment on ART. ${ }^{4,5}$ This study examines the causal impact of ART on one key dimension of household welfare - household food security. The attainment of household food security is a part of the second UN sustainable development goal, "End hunger, achieve food security and improved nutrition and promote sustainable agriculture"; ART is an important instrument to achieve the third sustainable development goal, "Ensure healthy lives and promote well-being for all at all ages". ${ }^{1}$ The net effect of ART on food security is theoretically ambiguous (Figure 1). Several studies have shown that food insecure households have lower adherence rates to ART and that over time there appears to be a positive association between ART and household food security. ${ }^{15,17,18,19}$ Other studies show that HIV patients initiating ART quickly regain their appetites and also require relatively more food than in their previous sick state, which may place pressure on limited household resources in the presence of delayed employment recovery. ${ }^{5,16}$ However, all of these studies rely on non-experimental approaches 
and likely suffer from omitted variable confounding and reverse causality. The problems for causal inference studies arise in non-experimental studies because of simultaneous impact of ART initiation on household socio-economic wellbeing paired with the corresponding impact of socio-economic wellbeing on the probability of ART access and adherence. To improve upon the previous literature, our study adopts a quasi-experimental approach to control for both omitted variable confounding and reverse causality by identifying quasi-random variation in ART eligibility. This approach allows a strong causal interpretation of our results. As such, our analysis lessens the directional uncertainty and improves the accuracy of estimates allowing us to reconcile some of the opposing insights from medicine, theory, and associational analyses on the relationship between ART and household food security.

The remainder of this study explores the relationship between ART initiation and household food security by exploiting an exogenous policy threshold over CD4 count, which was used to determine whether or not a patient was eligible to initiate ART. Utilizing this policy and longitudinal data from individual surveys and clinical patient records, we provide some of the first direct evidence of the causal effect of ART on household food security in rural South Africa, a location with one of the highest rates of HIV prevalence and incidence in the world. ${ }^{17}$

\section{Data and Methods}

\subsection{Data}

Our data is from the Wellcome Trust-funded Africa Health Research Institute (AHRI) in Somkhele, South Africa. AHRI, previously known as the Africa Centre for Population Health, has collected population-based longitudinal medical and socio-demographic data since 2000 through regular household survey visits on a cohort of more than 100,000 people living in a 167-square-mile area in northern

KwaZulu-Natal. ${ }^{20}$ As part of the population surveillance, seven waves of socioeconomic surveys were conducted during the period 2001-10 and four waves of health surveys during the period 2005-08. The population surveillance collects information on topics such as births, economic indicators, and food security. Additionally, AHRI's ART Evaluation and Monitoring System (ARTemis) has collected ART patient data from all public-sector clinics in the surveillance area. The ARTemis data include HIV Status, 
CD4 counts, and ART status of 6,681 adults residing in the population surveillance area over the 20012010 time period. ${ }^{19}$ To form out dataset, we linked individual level data from ARTemis to household data in the population surveillance dataset using a unique individual and a unique household identification number. Our study population includes all adults over the age of 18 who have (1) an initial CD4 count reading in one of the public-sector clinics in the surveillance area prior to 2010, (2) a baseline food security reading prior to their initial CD4 count reading, and (3) food security information after their initial CD4 count reading. These criteria give us a sample size of 5540 unique observations. Additional details on the AHRI population surveillance and the demographic and economic composition of the population can be found in a cohort profile published by Tanser and collegues. ${ }^{20}$

\subsection{Definition Of Exposure}

The exposure of interest was initiating ART within 6 months of an initial CD4 count reading. However, it is possible that actually receiving ART may be influenced by factors other than CD4 count level such as physician's perception of illness, community standing, or even the ability of patients to pressure doctors to initiate a patient on ART, regardless of CD4 count. Given these possibilities, we use an individual having an initial CD4 count reading below the 200 cells/ $\mu \mathrm{L}$ threshold as an instrumental variable

(IV) for ART. This instrument is valid for individuals within a narrow CD4 count bandwidth around the 200 cells $/ \mu \mathrm{L}$ threshold. The reason for instrument validity within a narrow bandwidth around the ART eligibility threshold is measurement error, which serves as a quasi-random allocation device assigning individuals whose true CD4 count is close to the threshold to immediate versus delayed ART eligibility. Stated differently, measurement error (and lack of manipulation of the running variable - see below) guarantees that the key assumption of the regression discontinuity design - the continuity of potential outcomes across the threshold - is met.

To create the actual exposure variable we first create a binary variable for having a CD4 count below 200 cells $/ \mu \mathrm{L}$ at earliest CD4 count reading and adopt a two-stage least squares estimation methodology. In the first-stage, our CD4 count indicator is regressed on an indicator for whether the individual was enrolled in ART within the following 6 months. Fitted values representing the probability 
that an individual was on ART if they had a CD4 count below 200 cells/ $\mu \mathrm{L}$ were predicted and utilized as the exposure in the second-stage linear probability model. To demonstrate the discontinuity in the probability of ART at the 200 cells/ $\mu \mathrm{L}$ threshold, the change in probability of ART initiation in our sample is displayed in Figure 2. In the terminology of regression discontinuity designs, this type of discontinuity is referred to as 'fuzzy', because the probability of ART initiation does not change from 1 to zero at the threshold, as would be the case in a 'sharp' discontinuity. Since many individuals in the study will eventually go onto ART, the exposure represents the initiation of ART relatively earlier compared to relatively later among individuals whose characteristics are the same in expectation.

\subsection{Outcome Measures}

We utilize the three measures of food security available in the AHRI data as outcomes. All three measures of food insecurity only capture one, relatively severe, dimension of food insecurity - having to forgo an entire meal due to financial reasons. Other relevant dimensions of food security, including having an adequate amount of food at each meal and consuming the food that an individual prefers, were not measured in this setting. As such, the outcome measures are more directly an indicator for severe food insufficiency, rather than an indicator for all types of food insecurity. Our first outcome measure indicates whether the adult surveyed missed a meal in the past month for financial reasons. The second outcome measure indicates whether any adult in the household of the surveyed adult missed a meal in the past month for financial reasons. The third outcome measure indicates whether any child living in the household of the surveyed adult missed a meal in the past month for financial reasons. In general, households in this sample have relatively low food insecurity, with between $1 \%$ and $8 \%$ of households reporting food insecurity in any given year, as presented in Figure 3. While this is unusual in many developing settings, members of the AHRI surveillance area have routinely had higher formal employment rates and greater household socioeconomic stability due to receipt of government grants and support, than many other localities within subSaharan Africa. ${ }^{20}$

\subsection{Statistical Methods}

We adopt a regression discontinuity design (RDD) to measure the impact of ART initiation on household food security. Our data lends itself to a RDD, because over our study period (from 2003 through 
2010) having a CD4 count reading below 200 cells $/ \mu \mathrm{L}$ acted as a threshold for being eligible for ART and CD4 count is a continuous biologic variable..$^{522,29}$ Two criteria are required for a RDD. First, one must have a continuous running variable that is not precisely manipulated by the observed or by those responsible for recording the data. ${ }^{22}$ Lack of precise manipulation and measurement error in the running variable guarantee that the standard sufficient assumption for valid RDD, the continuity assumption, holds. The second criterion is a threshold in the running variable that does not reflect a naturally occurring biological or other threshold, which results in a discontinuous change in the probability of ART exposure. ${ }^{23}$ CD4 count meets the first requirement in our study since it is continuous and can only be measured with random error, so patients are unable to precisely manipulate their own initial CD4 count. There is, however, potential for clinicians to record CD4 counts inconsistent with biologic readings. To examine whether this is the case, we plot the frequency distribution of CD4 counts around the 200 cells/ $\mu \mathrm{L}$ threshold. If clinicians systematically record CD4 counts below 200 cells $/ \mu \mathrm{L}$ for patients who appeared sicker so that they could receive ART, then this would bias our results on the impact of ART on food security. It would also result in a discontinuous frequency distribution at 200 cells $/ \mu \mathrm{L}$. However, the distribution of CD4 counts at the threshold is smooth and thus, it is unlikely that this type CD4 count alteration was prevalent (Figure 4). Employing a formal test for treatment manipulation utilizing the methodology developed by Cattaneo and colleagues confirms the visual evidence. ${ }^{24}$ The formal test yields a p-value of 0.2618 and thus fails to reject the null hypothesis of a smooth density across the threshold. The second requirement also holds because there is a significant discontinuity in the probability of ART initiation within 6 months of initial CD4 count reading at the 200 cells $/ \mu \mathrm{L}$ threshold and this discontinuous jump is not associated with any other sharp biological thresholds or direct access to available interventions or programs other than ART (Figure 2). Finally, including continuous CD4 count along with predicted ART status controls for nonsharp biological differences in outcomes over CD4 counts, such as susceptibility to opportunistic infections.

\subsection{The Model}

To generate the causal estimates of ART on household food security, we adopted a RDD utilizing a two-stage least squares IV framework. In the first stage, we regressed Exposure $_{i}$, a binary variable for whether individual $i$ is below 200 cells $/ \mu \mathrm{L}$ at initial CD4 count measurement, on $A R T_{\mathrm{i}}$, an indicator for 
whether or not the individual received ART within six months of initial CD4 count measurement.

$$
A R T_{i}=\alpha_{i}+\beta \text { Exposure }_{i}+\varepsilon_{i}
$$

Since the 200 cells/ $\mu \mathrm{L}$ CD4 count eligibility threshold is exogenously determined, correlated with actual ART initiation within 6 months, and uncorrelated with underlying biological discontinuities or existing policies, it can serve as an instrument for ART initiation for individuals within a narrow bandwidth of the threshold. From this first stage, we obtained predicted ART status, $\widetilde{A R T}_{l}$, and estimated a secondstage linear probability model of the form:

$$
\begin{aligned}
& Y_{i t}=\alpha_{i t}+\rho \widetilde{A R T}_{l}+\beta_{t}\left(\widetilde{A R T}_{l} * T_{t}\right)+\gamma\left(C D 4 \text { Count }_{i}-200\right)+\pi\left[\left(C D 4 \text { Count }_{i}-200\right) * \text { Exposure }_{i}\right] \\
& +T_{t}^{\prime} \delta+\varepsilon_{i t}
\end{aligned}
$$

Where $\widetilde{A R T}_{l}$ is the exposure-instrumented probability of being on ART, CD4 Count $t_{i}$ is the running variable of initial CD4 count measurement of individual $i, Y_{i t}$ is the household food security outcome measure for individual $i$ 's household in survey time period $t$, and $T_{t}$ are binary variables for years since initial CD4 measurement. In this model we interacted $\widetilde{A R T}_{l}$ with the binary variables for years since initial CD4 count measurement (up to the maximum of 6 years) to obtain the causal effect estimates, $\beta_{t}$. We then re-estimated the model adding covariates, including sex and age at initial CD4 count measurement in both stages, which may sociologically or behaviorally confound results. Additionally, an indicator for whether the individual had died as of time $t$ since initial CD4 count measurement was included to ensure that differences in treatment effects over time are not driven by survivor bias. The final second-stage model is:

$$
\begin{gathered}
Y_{i t}=\alpha_{i t}+\rho \widetilde{A R T}_{l}+\beta_{t}\left(\widetilde{A R T}_{\imath} * T_{t}\right)+\gamma\left(\text { CD4 } \text { Count }_{i}-\text { Cutoff }\right)+\pi\left[\left(\text { CD4 } \text { Count }_{i}-\text { Cutoff }\right)\right. \\
\left.* \text { Exposure }_{i}\right]+T_{t}{ }^{\prime} \delta+X_{i}^{\prime} \varphi+\theta D_{i}+\varepsilon_{i t}
\end{gathered}
$$

where $X_{i}$ represents a vector of individual controls for baseline age and sex, and $D_{\mathrm{i}}$ is an indicator for whether the individual dies during our survey period after initial CD4 treatment. Treatment effects are robust to the inclusion of these covariates as well as the inclusion of additional baseline household-level covariates including receiving a disability grant, household size, household head education level, and wealth quintile. $\beta_{t}$ gives the causal estimates for the impact of ART initiation on household food security 
over each of the $t$ time periods. The final estimates are obtained over a bandwidth of 100 cells $/ \mu \mathrm{L}$ around the 200 cells/ $\mu \mathrm{L}$ threshold, which was selected as the median optimal bandwidth derived from standard and bias-corrected mean squared error bandwidth selector functions and coverage error rate bandwidth selector functions. ${ }^{25}$

\section{Results}

\subsection{Main Results}

ART causes a significant increase in the probability of food insecurity in the first year of ART initiation, which diminishes to 0 within 1 to 3 years after initiation, depending on the outcome measure examined. In the period between ART initiation and one year after initiation, the estimated complier average causal effect (CACE) demonstrates that ART initiation significantly increases the probability that (1) the surveyed adult in the household had missed food by 10.2 percentage points (coefficient $=0.102$, $95 \% \mathrm{CI}=[0.039,0.166]),(2)$ any adult in the household had missed a meal by 15.2 percentage points (coefficient $=0.152,95 \% \mathrm{CI}=[0.073,0.231]),(3)$ any child in the household had missed a meal by 8.9 percentage points (coefficient $=0.0898,95 \% \mathrm{CI}=[0.0317,0.148])$. CACE here refers to the local average treatment effect at the 200 cells $/ \mu \mathrm{L}$ threshold among compliers, or those who initiate ART when below 200 cells/ $\mu \mathrm{L}$ and do not initiate ART when above the 200 cells $/ \mu \mathrm{L}$ threshold. Figure 5 displays the fitted RDD for all three food security outcome measures, controlling for covariates. The upper bound on the causal estimates obtained is an approximately 23 percentage point increase in household food insecurity as a result of ART initiation, corresponding to well over a $100 \%$ increase.

The impact of ART on household food security, for all outcome measures, diminishes to zero by the end of the third year after ART initiation (Table 1). The probability of a child in the household missing a meal increases to a lesser extent and diminishes to zero more rapidly than the probabilities of the surveyed adult missing food or any adult in the household missing a meal as a result of ART initiation. The data support the notion of reduced child outcome severity, because child food security recovers 1 period faster than for adult food security. The general trends exhibited in the simple model are robust to controlling for age, sex, death, and year fixed effects (Table 1), which help to eliminate the possibility that 
results are driven by survivor bias, temporal, or sex-specific confounders. Sex is an important control, as slower recovery time for women and differential ART uptake by sex have been shown. ${ }^{26}$ Figure 6 illustrates our estimated effects of ART initiation on household food security over time.

To test whether observations just above the 200 cells/ $\mu \mathrm{L}$ CD4 count discontinuity are valid counterfactuals for those below the discontinuity within our bandwidth, we examined balance over available individual and household covariates. Table 2 presents the means for each demographic covariate about the threshold. We used a two-group Hotelling's T-squared test to examine the joint equality of means between the two groups. The test gives an F-statistic of 1.0476 and associated p-value of 0.4232 from which we fail to reject the null hypothesis of balance over covariates between individuals above and below the 200 cells $/ \mu \mathrm{L}$ CD4 count threshold within the optimal 100 cells $/ \mu \mathrm{L}$ bandwidth. This result provides empirical evidence that those just above the CD4 count threshold are statistically appropriate counterfactuals to those below the threshold over the observable dimensions.

\subsection{Robustness Checks}

In order to further support a causal interpretation of the results, we used several robustness checks. For the first check, the significance and magnitude of coefficients were examined over multiple CD4 bandwidths about the 200 cells/ $\mu \mathrm{L}$ CD4 count threshold. In addition to the optimal 100 cells/ $\mu \mathrm{L}$ CD4 count bandwidth, we also employed bandwidths of 50, 100, 200, 300, 400 and then included the entire sample to see if results varied significantly. The results in Table 3 show that while the coefficients decrease slightly as the sample size expands, the direction and significance is still large during the first 2 years and diminishes for the following 4 periods, consistent with our initial estimates. The reduction in effect size with increasing bandwidth is not unusual because more healthy individuals, who are more likely to be food secure, will now be included in the control group, which will tend to alter the slope of the line fitted on the right side of the threshold (>200 cells $/ \mu \mathrm{L}$ CD4 count) without having much effect on the slope of the line

fitted on the left-hand side ( $<200$ cells/ $\mu \mathrm{L}$ CD4 count). The resulting discontinuity at the threshold may then appear less than it does within a smaller bandwidth. Despite this effect, the results obtained with a 100 cells/ $\mu \mathrm{L}$ CD4 count bandwidth are empirically supported when the full sample is taken into account. 
To ensure that the causal estimates are due to exogenous variation in treatment assignment generated by the 200 cells $/ \mu \mathrm{L}$ CD4 count threshold, we generated false thresholds at the $100,300,400$, and 500 cells/ $\mu \mathrm{L}$ CD4 count marks and repeated the analysis using each of these thresholds as the instrument for ART initiation within six months. The results displayed in Table 4 show that no estimates are even mildly significant for any of these thresholds at any time period after the initial CD4 reading. These checks demonstrate that our ART impact estimates are indeed most likely a direct result of the exogenous variation in the probability of ART initiation at the 200 cells/ $\mu \mathrm{L}$ CD4 count threshold and not due to chance or some other property of our data. In addition to lending credibility to the results, the robustness checks verify that, regardless of specification, the results fall in the same range from a 4 to 18 percentage-point absolute increase in household food insecurity because of ART initiation. Since the baseline probability of an adult missing food in the past month is 0.022 (or $2.2 \%$ chance of adult food insecurity) in our population, the lower bound estimate of a 4 percentage-point increase is equivalent to a $181 \%$ relative increase in household food insecurity while the upper bound of an 18 percentage-point increase is equivalent to a $818 \%$ relative increase in adult food insecurity as a result of ART initiation. The baseline probability of a child having missed a meal in the past month is 0.017 (or $1.7 \%$ chance of child food insecurity). The range of absolute treatment effect estimates over children within the household range in magnitude from a 1.6 percentage-point increase to a 12.0 percentage-point increase in child food insecurity. These effect sizes equivalent to $94 \%$ and $750 \%$ relative increases, respectively.

\section{Discussion}

Contrary to previous evidence, our results show that for one to three years after initial CD4 count measurement, there are adverse effects of ART on household food security affecting both adults and children. ${ }^{15,17}$ While the results appear to contradict previous research, the study by Weiser and colleagues on the same topic does indicate that after controlling for a physical health score, the positive impact of ART on household food security is no longer significant. ${ }^{15}$ The authors hypothesize that this is due to patients regaining physical health and being able to work again, citing that employment and hours worked increase 
after six months of ART initiation. ${ }^{15}$ We know from previous research in our population that employment gains are delayed between 2-3 years after ART initiation, which may suggest why the adverse effects of ART on food security disappear after 3 years. ${ }^{5}$ Additionally, Weiser and colleagues discuss that they did not have access to a non-ART comparison group and as such, the observed downward trends in food insecurity and physical health status could be explained by general downward population trends in food security over the three-year period. ${ }^{15}$ Our analysis demonstrates that this is in fact an issue for our population, which does exhibit general downward trends in food security over time (Figure 2). By adopting an RDD approach and isolating quasi-random variation in ART status, we are able to avert the potential bias due to general population trends and establish causal impact estimates.

Our approach also provides a substantial methodological improvement on the previous study by Palar and colleagues, which demonstrated differences in food security between ART patients and non-ART comparator groups. ${ }^{17}$ Because ART was not (quasi-)randomly assigned in this study, the presence of differences between the ART group and non-ART comparator groups could indicate selection and confounding rather than causal effects. Our exploitation of a quasi-random eligibility threshold, over which we examine effects, can control for all unobserved confounders. As such, the effect estimates we generate are derived utilizing a comparator group that is likely to be a valid counterfactual for people who initiate ART.

The results of our study are consistent with both the hypothesis that adults regain appetite quickly while on ART (which puts pressure on limited household nutritional resources) as well as the hypothesis that the indirect costs of ART (such as transportation costs) may cause households to divert a larger share of household resources to the ART recipient. If the households face significant resource constraint due to a member's ART initiations and the household member on ART is unable to contribute more to household earnings or food supply, then we would expect household food security to be reduced, which is what our results suggest. Indeed, a study by Chimbindi and colleagues in this population found that the transportation and time costs associated with nominally free ART treatment is equivalent to over a third of median per capita income and that $39 \%$ of ART patients needed to borrow or sell financial assets in order 
to meet these high costs. ${ }^{27}$ Moreover, as labor outcomes typically recover after 2-3 years on ART, we would expect the negative impacts on household food security to diminish around this time, which is what our results show. ${ }^{10}$ In addition to increased resource utilization, the ART effects on food insecurity could also be due to the recovery of appetite on ART. An adult whose appetite increases will not only be more likely to report food insecurity but also consume more food, affecting the food security of other household members.

The fact that food insecurity among children increases when an adult household member starts taking ART indicates that the impact of ART on household resources is severe, because households typically attempt to shield children from adverse nutritional shocks, e.g., by devising new ways to manage food supplies. ${ }^{28}$ Our result that child food insecurity diminishes faster than adult food insecurity indicates that households do indeed prioritize children's nutrition, but that the negative impact of ART on household resources is so severe that behavioral responses to avert hunger in children are insufficient in the short term. Future qualitative research could shed greater light on the precise mechanisms leading form ART initiation to food insecurity in this population.

The limitations of our study primarily relate to the generalizability of the causal estimates. Food insecurity in the study area is relatively low and formal employment, as opposed to agricultural employment, is relatively high when compared with other regions in sub-Saharan Africa. This may cause the relationship between ART initiation and household socioeconomic status to be more delayed and potentially less strong than in primarily agrarian households where labor participation on household farms may gradually rebound. Additionally, in terms of illness progression, our results are generalizable only to those who initiate ART when relatively sick - at a CD4 count level around 200 cells/ $\mu \mathrm{L}$ - rather than to those who initiate ART at higher CD4 count levels. However this limitation may currently not be severe, because despite the fact that eligibility thresholds in South Africa have risen over time, it is still the case that many individuals do not receive CD4 count testing until they are very ill. Overall, the distributions of initial CD4 counts in sub-Saharan Africa has only slowly shifted to higher values over the past decade and mean initial CD4 counts remain far below eligibility thresholds. As such, it is likely that our results will continue to hold even in the absence of ART eligibility thresholds. 
A final limitation is the measure of food security collected in the population-based surveillance. Having missed a meal in the past month is a relatively coarse measure and only captures one dimension of food security, food insufficiency, rather than other dimensions including not having enough food at each meal or not having desired foods. The one-dimensionality of our food security outcome measure is likely one factor contributing to the overall low prevalence of food insecurity in this population. Despite this limitation in measuring the full scope of food insecurity, if the mechanisms we hypothesize to explain our results hold true, it is likely that the ART impact on other dimensions of food security would at least be as severe as the impact we demonstrate. Additionally, approximately $50 \%$ of our sample, equally distributed above and below the threshold, reported receiving some type of government food assistance, which is likely to have mitigated the impact of ART on food insecurity in this population. In populations without any government food assistance, the ART impact on food security may be more severe.

Our results have one key policy implication: Food or financial support for ART patients in the first years on treatment will likely be helpful in reducing the negative impact of ART on food security. Such support interventions will be all the more important because ART leads to food insecurity not only among ART patients but also among their children and other household members. In designing such an intervention, the time-limited nature of support, which our findings suggest, ensures that the required resources to fund the intervention will not grow continuously but will change in close alignment with the number of patients having recently initiated ART. While a food or financial support intervention is likely to improve food security (Palar et al., 2015), it may also have several important behavioral consequences. First, among ART patients it is likely to increase retention in care, because remaining on ART will ensure continued access to food or financial support. Second, among ART patients, this support may increase adherence because it is far easier to swallow pills with than without food. Moreover, hunger and the absence of sufficient food may exacerbate ART side effects (Singer et al., 2015) and a food security-enhancing intervention may thus improve ART tolerability and adherence. Finally, among patients needing but not yet receiving ART, knowledge of the fact that food or financial support accompany ART 
may reduce barriers to ART initiation. The support intervention may thus increase demand for needed ART.

\section{Conclusion}

ART increases household food insecurity; however, this effect disappears over time. There are two primary channels through which ART initiation is likely to affect household food security, and it is likely that a combination of both are contributing to the total effect. The first channel is through appetite recovery and the resulting greater likelihood of reporting hunger $;{ }^{16}$ the second channel is the use of household resources for ART utilization. In the longer term the negative effects of ART on food insecurity disappear, most likely because over time ART improves employment and income. The key policy implication of our findings is that additional food or financial support for people who have recently initiated ART will likely help to avoid household food insecurity.

\section{Author Contribution}

Bryan N. Patenaude, Sc.D: Devised methodology, data collection, study design, statistical analysis, data interpretation, figures, manuscript writing \& preparation.

Natsayi Chimbindi, MSc: Literature search, database management, writing.

Dr. Deenan Pillay, PhD: study design, data interpretation.

Dr. Till Bärnighausen, Sc.D., M.D.: study design, data collection, methodology, literature search, data interpretation, writing

\section{Conflicts of Interest}

None.

\section{References}

1. Nino FS. Hunger and food security [Internet]. United Nations Sustainable Development. [cited 2016 Aug 12]. Available from: http://www.un.org/sustainabledevelopment/hunger/ 
2. Rosegrant MW, Cline SA. Global food security: challenges and policies. Science. 2003 Dec 12;302(5652):1917-9.

3. Baker JV, Peng G, Rapkin J, Abrams DI, Silverberg MJ, MacArthur RD, et al. CD4+ count and risk of non-AIDS diseases following initial treatment for HIV infection. AIDS. 2008 Apr 23;22(7):8418.

4. Beard J, Feeley F, Rosen S. Economic and quality of life outcomes of antiretroviral therapy for HIV/AIDS in developing countries: a systematic literature review. AIDS Care. 2009 Nov;21(11):1343-56.

5. Bor J, Tanser F, Newell M-L, Bärnighausen T. In a study of a population cohort in South Africa, HIV patients on antiretrovirals had nearly full recovery of employment. Health Aff (Millwood). 2012 Jul;31(7):1459-69.

6. Coetzee C. The Impact of Highly Active Antiretroviral Treatment (HAART) on Employment in Khayelitsha. South African Journal of Economics. 2008 May 1;76:S75-85.

7. Egger M, May M, Chêne G, Phillips AN, Ledergerber B, Dabis F, et al. Prognosis of HIV-1-infected patients starting highly active antiretroviral therapy: a collaborative analysis of prospective studies. Lancet. 2002 Jul 13;360(9327):119-29.

8. Habyarimana J, Mbakile B, Pop-Eleches C. The Impact of HIV/AIDS and ARV Treatment on Worker Absenteeism Implications for African Firms. J Human Resources. 2010 Oct 2;45(4):809-39.

9. Rosen S, Ketlhapile M, Sanne I, Desilva MB. Differences in normal activities, job performance and symptom prevalence between patients not yet on antiretroviral therapy and patients initiating therapy in South Africa. AIDS. 2008 Jul;22 Suppl 1:S131-9. 
10. Rosen S, Larson B, Brennan A, Long L, Fox M, Mongwenyana C, et al. Economic outcomes of patients receiving antiretroviral therapy for HIV/AIDS in South Africa are sustained through three years on treatment. PLoS ONE. 2010;5(9):e12731.

11. Thirumurthy H, Zivin JG, Goldstein M. The Economic Impact of AIDS Treatment Labor Supply in Western Kenya. J Human Resources. 2008 Jul 1;43(3):511-52.

12. Thirumurthy H, Jafri A, Srinivas G, Arumugam V, Saravanan RM, Angappan SK, et al. Two-year impacts on employment and income among adults receiving antiretroviral therapy in Tamil Nadu, India: a cohort study. AIDS. 2011 Jan 14;25(2):239-46.

13. Cohen MS, Chen YQ, McCauley M, Gamble T, Hosseinipour MC, Kumarasamy N, et al. Prevention of HIV-1 infection with early antiretroviral therapy. N Engl J Med. 2011 Aug $11 ; 365(6): 493-505$.

14. Palar K, Derose KP, Linnemayr S, Smith A, Farías H, Wagner G, et al. Impact of food support on food security and body weight among HIV antiretroviral therapy recipients in Honduras: a pilot intervention trial. AIDS Care. 2015;27(4):409-15.

15. Weiser SD, Gupta R, Tsai AC, Frongillo EA, Grede N, Kumbakumba E, et al. Changes in food insecurity, nutritional status, and physical health status after antiretroviral therapy initiation in rural Uganda. J Acquir Immune Defic Syndr. 2012 Oct 1;61(2):179-86.

16. Rehman AM, Woodd S, Chisenga M, Siame J, Sampson G, PrayGod G, et al. Appetite testing in HIV-infected African adults recovering from malnutrition and given antiretroviral therapy. Public Health Nutr. 2015 Mar;18(4):742-51. 
17. Palar, K. a, Wagner, G. b, Ghosh-Dastidar, B. b, \& Mugyenyi, P. c. (2012). Role of antiretroviral therapy in improving food security among patients initiating HIV treatment and care. [Miscellaneous Article]. AIDS, 26(18), 2375-2381.

https://doi.org/10.1097/QAD.0b013e328359b809

18. Singer A, Weiser S, McCoy S. Does Food Insecurity Undermine Adherence to Antiretroviral Therapy? A Systematic Review. AIDS and Behavior. 2015;19(8):1510-26.

19. Weiser D, Palar A, Frongillo C, Tsai W, Kumbakumba R, Depee R, et al. Longitudinal assessment of associations between food insecurity, antiretroviral adherence and HIV treatment outcomes in rural Uganda. AIDS. 2014;28(1):115-20.

18. Bor J, Bärnighausen T, Newell C, Tanser F, Newell M-L. Social exposure to an antiretroviral treatment programme in rural KwaZulu-Natal. Trop Med Int Health. 2011 Aug;16(8):988-94.

19. Tanser F, Hosegood V, Bärnighausen T, Herbst K, Nyirenda M, Muhwava W, et al. Cohort Profile: Africa Centre Demographic Information System (ACDIS) and population-based HIV survey. Int J Epidemiol. 2008 Oct;37(5):956-62.

20. Bärnighausen T, Tanser F, Dabis F, Newell M-L. Interventions to improve the performance of HIV health systems for treatment-as-prevention in sub-Saharan Africa: the experimental evidence. Curr Opin HIV AIDS. 2012 Mar;7(2):140-50.

21. Bor J, Moscoe E, Mutevedzi P, Newell M-L, Bärnighausen T. Regression discontinuity designs in epidemiology: causal inference without randomized trials. Epidemiology. 2014 Sep;25(5):729-37.

22. Angrist JD, Pischke J-S. Mostly harmless econometrics: an empiricist's companion. Princeton: Princeton University Press; 2009. 373 p. 
23. Cattaneo MD, Jansson M, Ma X. Simple Local Regression Distribution Estimators with an Application to Manipulation Testing [Internet]. University of Michigan; 2016 [cited 2016 Aug 12]. Available from: http://www-personal.umich.edu/ cattaneo/papers/Cattaneo-JanssonMa_2016_LocPolDensity.pdf

24. Calonico S, Cattaneo MD, Titiunik R. Robust Nonparametric Confidence Intervals for RegressionDiscontinuity Designs. Econometrica. 2014 Nov 1;82(6):2295-326.

25. Larson BA, Fox MP, Rosen S, Bii M, Sigei C, Shaffer D, et al. Do the socioeconomic impacts of antiretroviral therapy vary by gender? A longitudinal study of Kenyan agricultural worker employment outcomes. BMC Public Health. 2009;9:240.

26. Chimbindi N, Bor J, Newell M-L, Tanser F, Baltusen R, Hontelez J, et al. Time and money: the true costs of health care utilization for patients receiving "free" HIV/TB care and treatment in rural KwaZulu-Natal. J Acquir Immune Defic Syndr. 2015 Oct 1;70(2):e52-60.

27. Haber N, Tanser F, Bor J, Naidu K, Mutevedzi T, Herbst K, Porter K, Pillay D, Bärnighausen T. From HIV infection to therapeutic response: a population-based longitudinal HIV cascade-of-care study in KwaZulu-Natal, South Africa. Lancet HIV. 2017 Jan 30. pii: S2352-3018(16)30224-7

28. Martin MA, Lippert AM. Feeding her children, but risking her health: The intersection of gender, household food insecurity and obesity. Social Science \& Medicine. 2012;74(11):1754-64.

29. Bor J., Fox M., Rosen S., Venkataramani A., Tanser F., Pillay D., et al. Treatment eligibility and retention in clinical HIV care: a regression discontinuity study in South Africa, PLOS Medicine, 14 (11), e1002463. 
Figure 1: Pathways from ART Initiation to Food Security

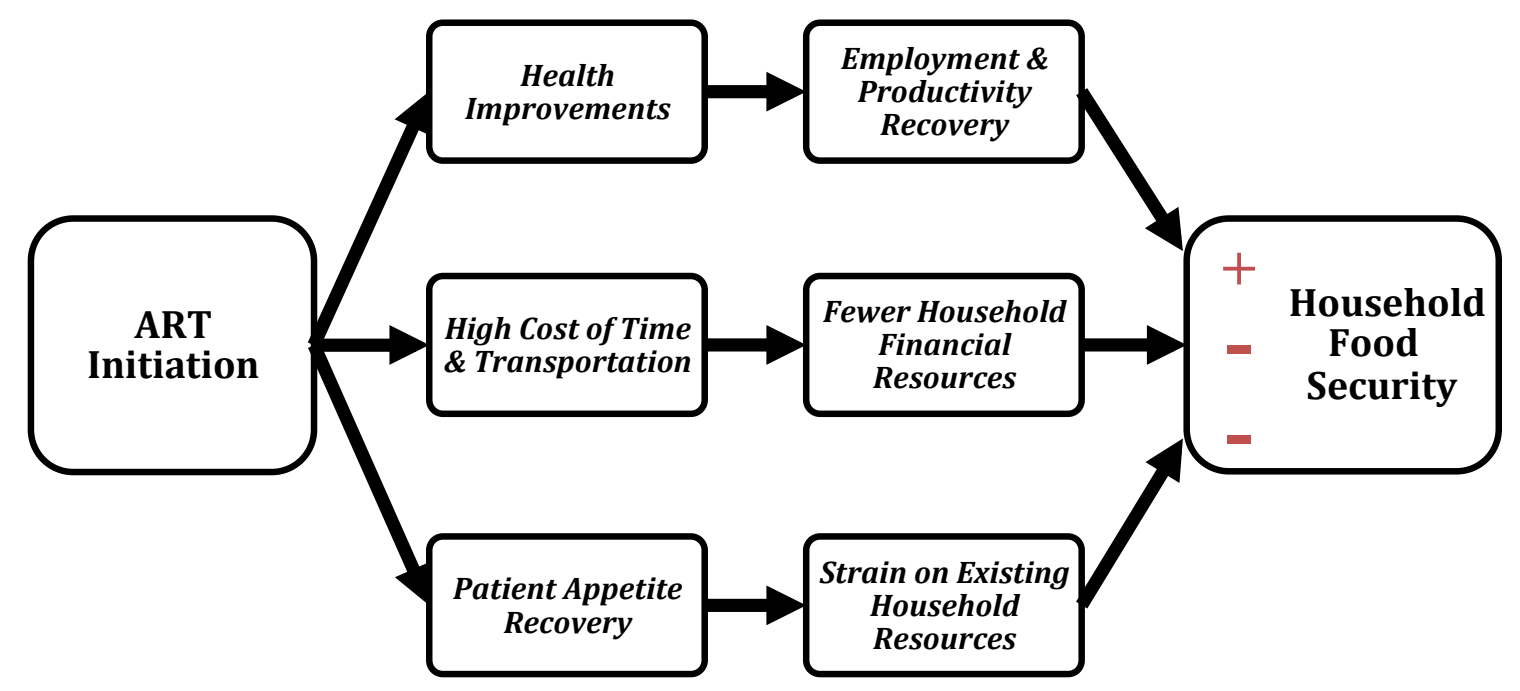


Figure 2: Probability of ART Initiation by Initial CD4 Count

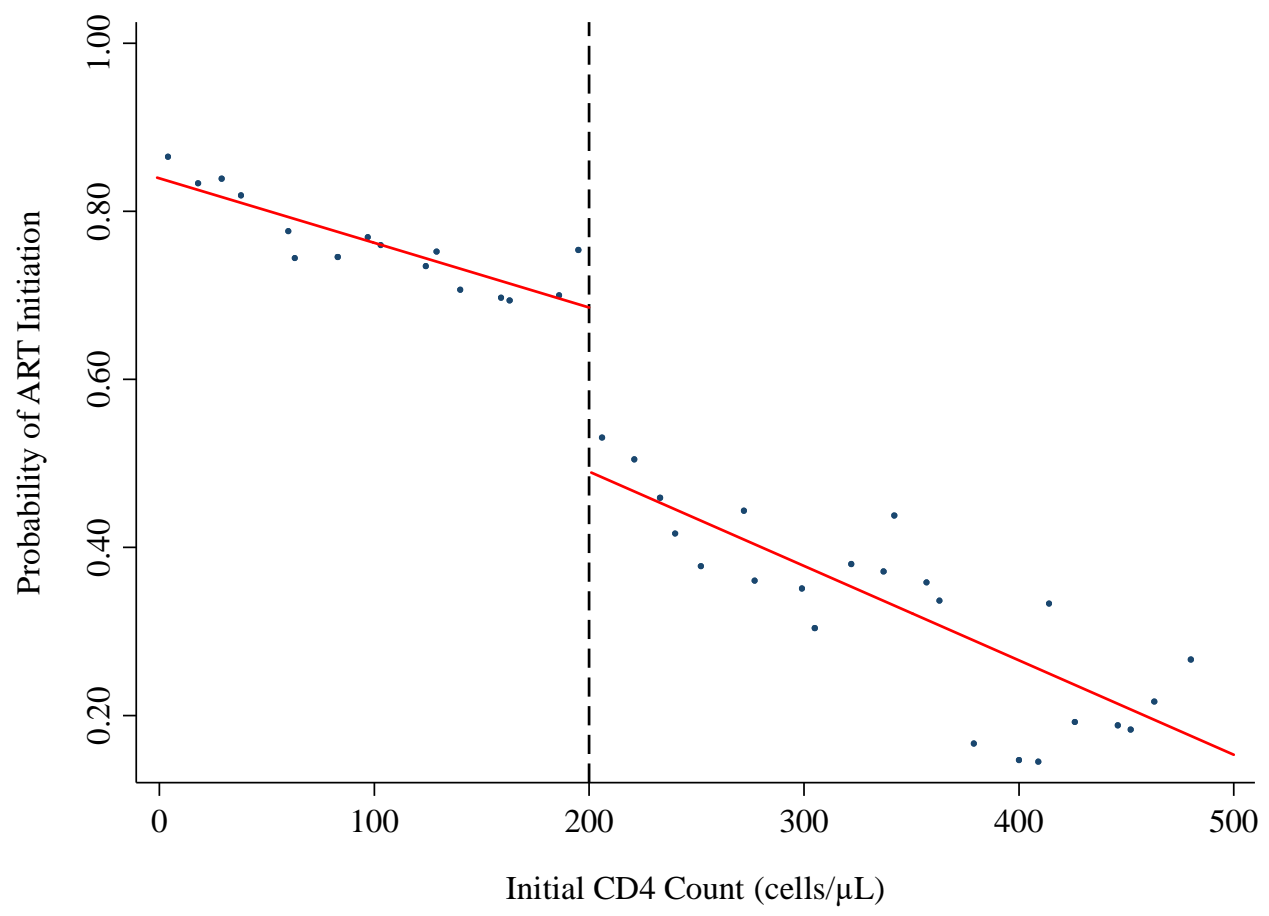

Notes: Blue points represent the average probability of being on ART within 6 months of initial CD4 count measurement. Each point represents a CD4 count bins of 20 cells $/ \mu \mathrm{L}$. Red lines represent the linear fitted probability of ART initiation on either side of the eligibility threshold. The dashed line at 200 cells $/ \mu$ L represents the CD4 count threshold used to determine ART eligibility from 2001-2010 in South Africa. Adopting a linear probability model, the slope of line below 200 cells $/ \mu \mathrm{L}$ is -0.0004 , $95 \%$ CI $[-0.0005,-0.0003]$, while the slope of the line above the 200 cells $/ \mu \mathrm{L}$ threshold is $-0.002,95 \%$ CI $[-0.0022,-0.0018]$. The size of the probability jump at the discontinuity is -0.154 points $95 \%$ CI [$0.2160364-0.0920957]$ with a p-value $<0.001$. 
Figure 3: Average Probability of Food Insecurity over Time
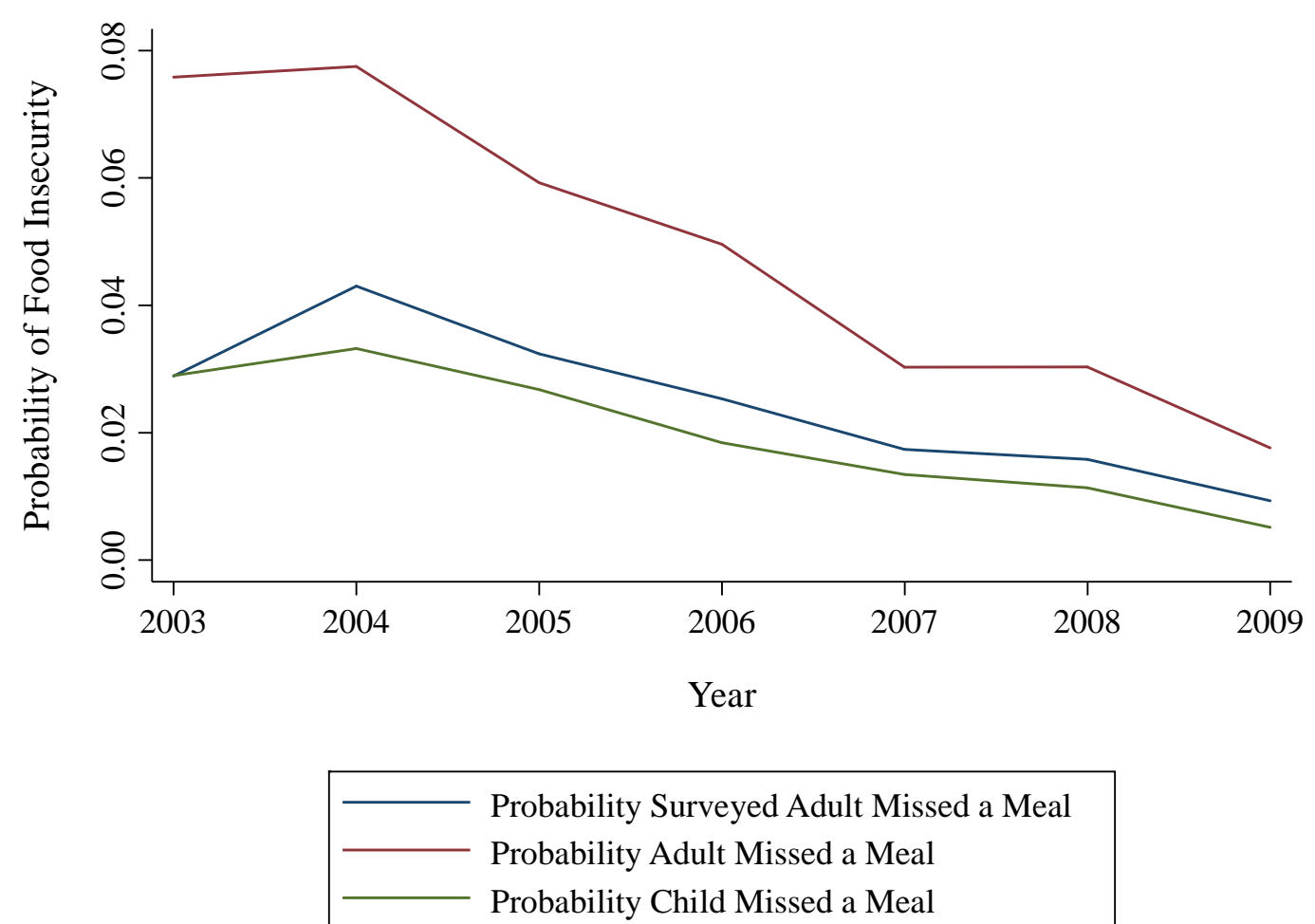

Notes: The colored lines represent average proportion of individuals reporting being food insecure on the corresponding food security outcome measure within our sample of 5540 individuals. 
Figure 4: Kernel Density Estimation of Initial CD4 Count Distribution

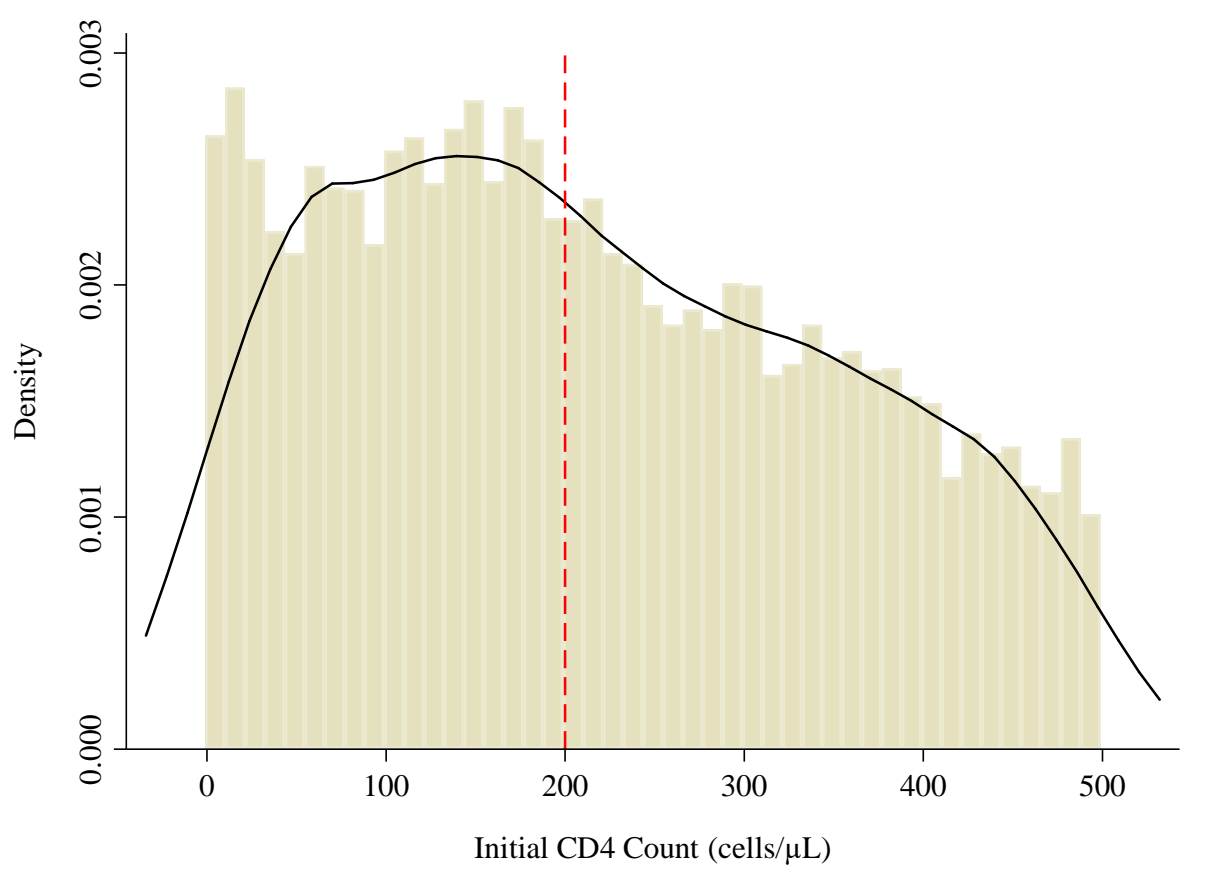

Notes: This figure examines the density of initial CD4 count about the 200 cells/ $\mu \mathrm{L}$ ART eligibility threshold to test for manipulation of CD4 count at the threshold. The blue line is a kernel density plot of the distribution of initial CD4 count utilizing an Epanechnikov kernel function. The bandwidth used for estimation is the optimal bandwidth of 12.71 that minimizes the mean integrated squared error if the data were Gaussian and a Gaussian kernel were used. The red dashed line represents the 200 cells/ $\mu \mathrm{L}$ ART eligibility threshold. No bunching is visually evident at the threshold over the histogram of CD4 counts (in bins of 10 cells $/ \mu \mathrm{L}$ ). A formal test for bunching described developed by Cattaneo and colleagues yields a pvalue of 0.2618 and fails to reject the null hypothesis of smooth density across the threshold, confirming the visual evidence. ${ }^{24}$ 
Figure 5: Regression Discontinuity Over Three Food Security Outcome Measures at $<1$ Year since Initial CD4 Count Measurement
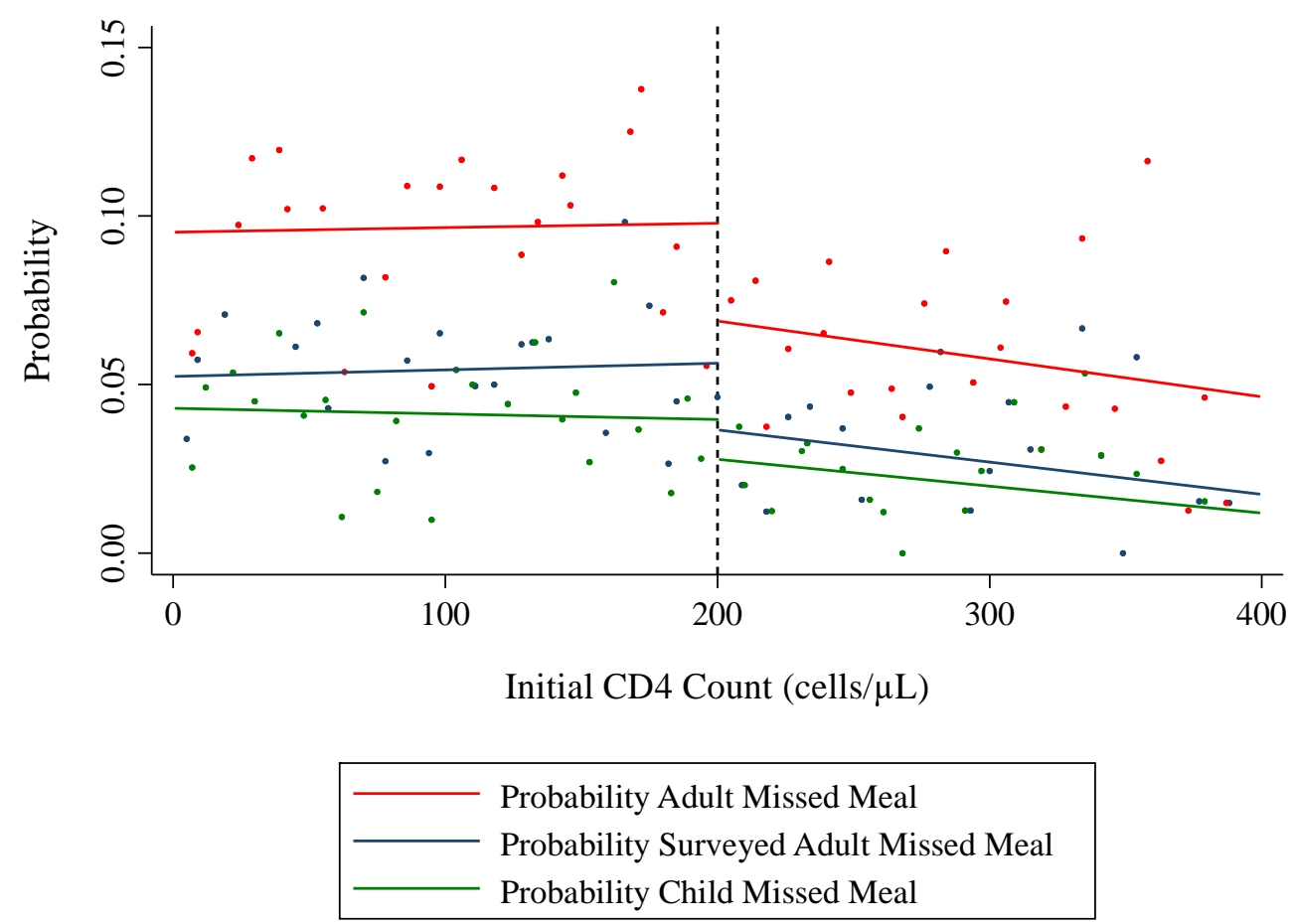

Notes: The colored lines represent fitted linear probabilities of the corresponding food security outcome measure over CD4 count on either side of the 200 cells/ $\mu \mathrm{L}$ ART eligibility threshold. The corresponding colored points reflect the underlying data in the form of average probabilities of the respective binary food security outcome over bins of $8 \mathrm{CD} 4$ cells $/ \mu \mathrm{L}$. The dotted line represents the ART eligibility threshold. The linear probability models are of the form described in the methods section. 
Figure 6: Impact of ART on Three Household Food Security Outcome Measures by Year Since Initial CD4 Count (Complier Average Causal Estimates)

Outcome 1: Probability Surveyed Adult Missed a Meal in the Previous 4 Weeks

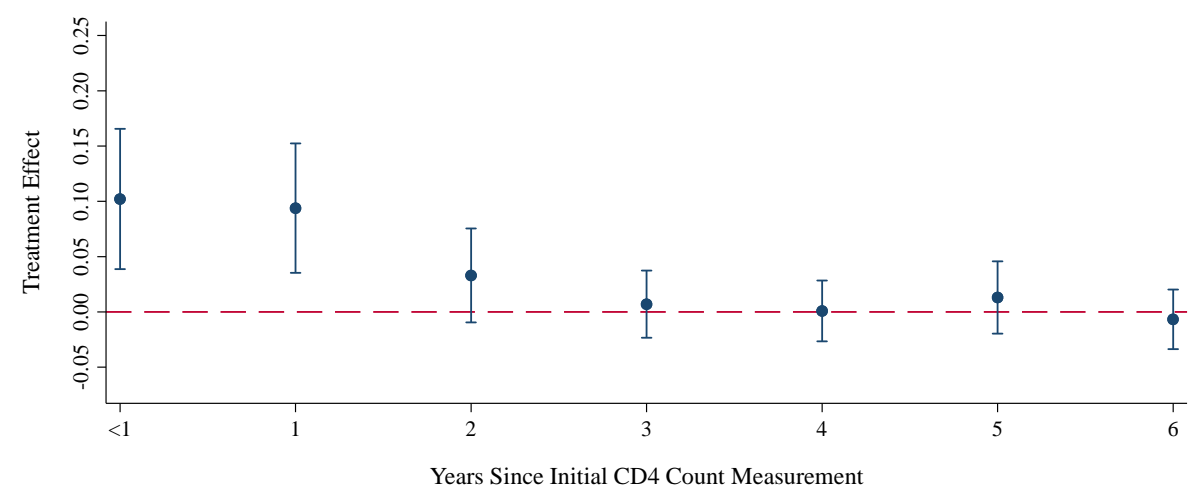

Outcome 2: Probability an Adult Missed a Meal in the Previous 4 Weeks

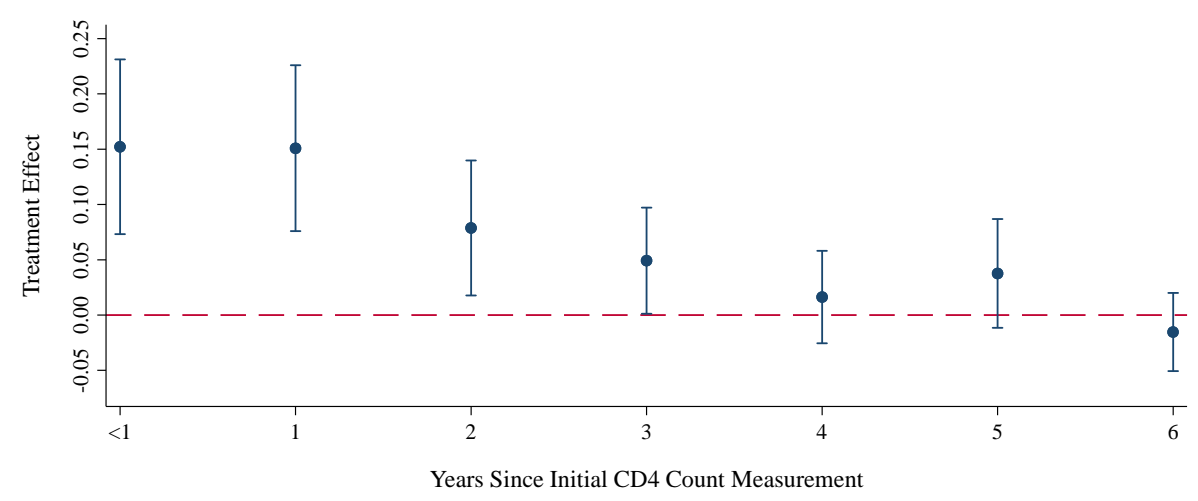

Outcome 3: Probability a Child Missed a Meal in the Previous 4 Weeks

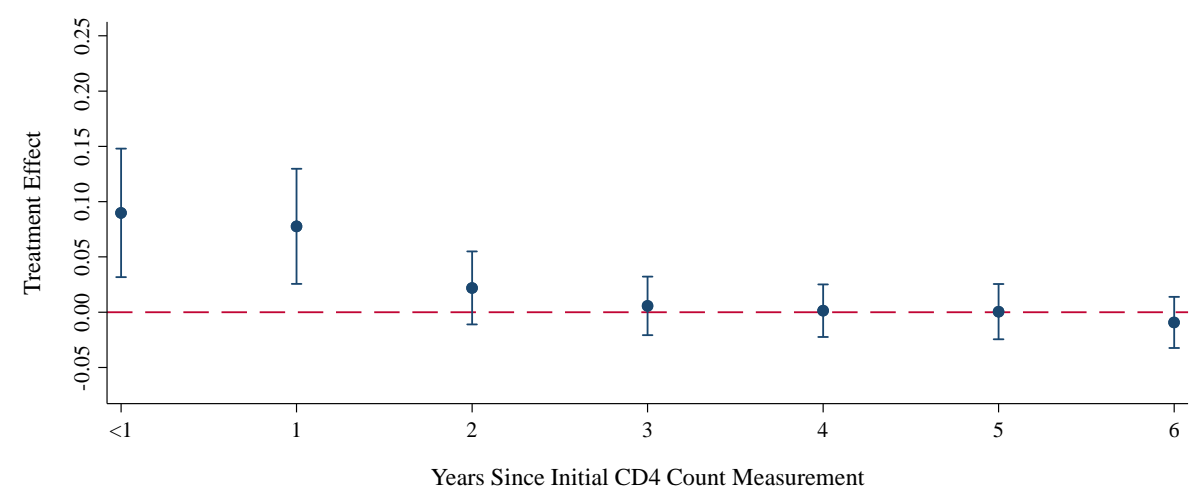

Notes: Points are complier average causal effect estimates for the three food security outcome measures at each time period since initial CD4 count measurement. 95\% confidence intervals are presented around the point estimates. The dashed line represents 0 , with confidence intervals crossing this line being statistically insignificant at the $5 \%$ level of significance. Estimates are the results of the two-stage least squares instrumental variables regressions described in the methods section. 
Table 1: Results for the Causal Effect of ART on Three Household Food Security Outcomes Over Time Since Initial CD4 Count Measurement

\begin{tabular}{|c|c|c|c|c|c|c|c|c|c|c|}
\hline \multirow{14}{*}{$\begin{array}{l}\text { Treatment } \\
\text { Effect by } \\
\text { Time Since } \\
\text { Initial CD4 } \\
\text { Count } \\
\text { Reading } \\
\text { Date }\end{array}$} & \multirow{3}{*}{$<1$ Year } & \multicolumn{3}{|c|}{$\frac{\text { Outcome Measure 1: Probability that Surveyed Adult }}{\text { Missed a Meal for Financial Reasons }}$} & \multicolumn{3}{|c|}{$\begin{array}{l}\text { Outcome Measure 2: Probability that Any Adult in } \\
\text { Household Missed a Meal for Financial Reasons }\end{array}$} & \multicolumn{3}{|c|}{$\begin{array}{c}\text { Outcome Measure 3: Probability that Any Child in Household } \\
\text { Missed a Meal for Financial Reasons }\end{array}$} \\
\hline & & $0.109 * * *$ & $0.0989 * * *$ & $0.102 * * *$ & $0.170 * * *$ & $0.142 * * *$ & $0.152 * * *$ & $0.0843^{* * *}$ & $0.0849 * * *$ & $0.0898^{* * *}$ \\
\hline & & {$[0.0579,0.160]$} & {$[0.0368,0.161]$} & {$[0.0388,0.166]$} & {$[0.107,0.233]$} & {$[0.0650,0.219]$} & {$[0.0732,0.231]$} & {$[0.0380,0.131]$} & {$[0.0281,0.142]$} & {$[0.0317,0.148]$} \\
\hline & 1 Year & $0.0648 * * *$ & $0.0841 * * *$ & $0.0938 * * *$ & $0.120 * * *$ & $0.134 * * *$ & $0.151 * * *$ & $0.0454 * * *$ & $0.0702 * * *$ & $0.0777 * * *$ \\
\hline & & {$[0.0255,0.104]$} & {$[0.0272,0.141]$} & {$[0.0353,0.152]$} & {$[0.0666,0.173]$} & {$[0.0613,0.206]$} & {$[0.0759,0.226]$} & {$[0.0109,0.0799]$} & {$[0.0197,0.121]$} & {$[0.0257,0.130]$} \\
\hline & 2 Years & $0.0342^{* *}$ & 0.0234 & 0.0330 & $0.0482^{* *}$ & $0.0553^{*}$ & $0.0788^{* *}$ & 0.0222 & 0.0143 & 0.0219 \\
\hline & & {$[0.00193,0.0666]$} & {$[-0.0156,0.0624]$} & {$[-0.00948,0.0755]$} & {$[0.00593,0.0905]$} & {$[-0.000757,0.111]$} & {$[0.0177,0.140]$} & {$[-0.00587,0.0503]$} & {$[-0.0160,0.0446]$} & {$[-0.0110,0.0549]$} \\
\hline & 3 Years & -0.000942 & -0.00285 & 0.00694 & 0.0182 & 0.0281 & $0.0492 * *$ & -0.00197 & -0.000321 & 0.00572 \\
\hline & & {$[-0.0250,0.0231]$} & {$[-0.0304,0.0247]$} & {$[-0.0234,0.0373]$} & {$[-0.0165,0.0529]$} & {$[-0.0168,0.0731]$} & {$[0.00126,0.0972]$} & {$[-0.0245,0.0206]$} & {$[-0.0244,0.0238]$} & {$[-0.0207,0.0321]$} \\
\hline & 4 Years & -0.00417 & -0.00711 & 0.000883 & -0.00720 & -0.00303 & 0.0163 & -0.00519 & -0.00521 & 0.00141 \\
\hline & & {$[-0.0266,0.0182]$} & {$[-0.0328,0.0186]$} & {$[-0.0266,0.0283]$} & {$[-0.0380,0.0236]$} & {$[-0.0413,0.0352]$} & {$[-0.0255,0.0581]$} & {$[-0.0261,0.0157]$} & {$[-0.0274,0.0170]$} & {$[-0.0224,0.0252]$} \\
\hline & 5 Years & 0.00222 & 0.00566 & 0.0131 & 0.00889 & 0.0211 & 0.0377 & -0.00519 & -0.00479 & 0.000524 \\
\hline & & {$[-0.0238,0.0282]$} & {$[-0.0247,0.0360]$} & {$[-0.0196,0.0458]$} & {$[-0.0270,0.0447]$} & {$[-0.0243,0.0664]$} & {$[-0.0115,0.0868]$} & {$[-0.0282,0.0178]$} & {$[-0.0278,0.0182]$} & {$[-0.0245,0.0255]$} \\
\hline & 6 Years & $\begin{array}{l}-0.00946 \\
{[-0.0324,0.0135]}\end{array}$ & $\begin{array}{l}-0.00913 \\
{[-0.0344,0.0162]}\end{array}$ & $\begin{array}{l}-0.00667 \\
{[-0.0337,0.0203]}\end{array}$ & $\begin{array}{l}-0.0262^{*} \\
{[-0.0555,0.00307]}\end{array}$ & $\begin{array}{l}-0.0220 \\
{[-0.0551,0.0110]}\end{array}$ & $\begin{array}{l}-0.0153 \\
{[-0.0507,0.0200]}\end{array}$ & $\begin{array}{l}-0.0106 \\
{[-0.0316,0.0104]}\end{array}$ & $\begin{array}{l}-0.00886 \\
{[-0.0306,0.0129]}\end{array}$ & $\begin{array}{l}-0.00919 \\
{[-0.0323,0.0139]}\end{array}$ \\
\hline \multirow{3}{*}{\multicolumn{2}{|c|}{$\begin{array}{l}\text { Age \& Sex Covariates } \\
\text { Indicator for Death } \\
\text { Time Fixed Effects }\end{array}$}} & & $X$ & $\mathrm{X}$ & & $\mathrm{X}$ & $\mathrm{X}$ & & \multirow{2}{*}{$\begin{array}{l}X \\
X\end{array}$} & $\mathrm{X}$ \\
\hline & & & $\mathrm{X}$ & $\mathrm{X}$ & & $\mathrm{X}$ & $\mathrm{X}$ & & & $\mathrm{X}$ \\
\hline & & & & $\mathrm{X}$ & & & $X$ & & $X$ & $\mathrm{X}$ \\
\hline & $N$ & 3216 & 3216 & 3216 & 3211 & 3211 & 3211 & 3209 & 3209 & 3209 \\
\hline
\end{tabular}

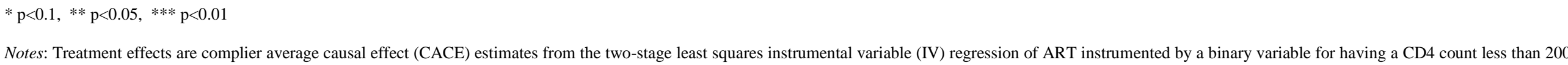

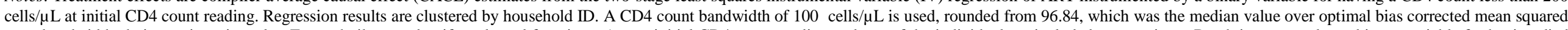

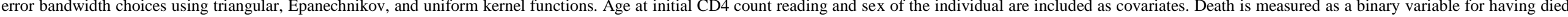

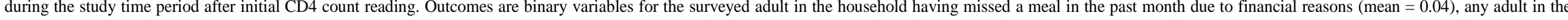

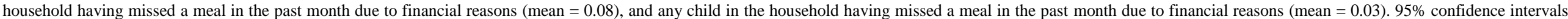
are in brackets. 
Table 2: Balance of Covariate Means above and below the 200 cells/ $\mu \mathrm{L}$ CD4 Count Eligibility Threshold within the Optimal 100 cells/ $\mu \mathrm{L}$ bandwidth

\begin{tabular}{|lcc|}
\hline Covariate & Below Threshold & Above Threshold \\
\hline Age at Initial CD4 Count & 34.10 & 34.89 \\
Proportion of Women & 0.71 & 0.76 \\
Proportion with Children & 0.84 & 0.85 \\
Number of Children & 2.60 & 2.88 \\
Having Been on ART Previously & 0.06 & 0.10 \\
Kilometers to Nearest Clinic & 2.62 & 2.63 \\
Kilometers to Nearest School & 1.82 & 1.77 \\
Kilometers to Nearest Primary School & 1.19 & 1.20 \\
Urban Proportion of Population & 0.45 & 0.41 \\
Asset Quintile & 3.03 & 3.18 \\
Asset Percentile & 51.16 & 53.94 \\
Proportion Employed & 0.22 & 0.22 \\
Child Support Grant Recipient & 0.02 & 0.03 \\
Disability Grant Recipient & 0.04 & 0.05 \\
Foster Care Grant Recipient & 0.00 & 0.01 \\
Perceived Financial Status & 10.76 & 10.31 \\
Old Age Pension Recipient & 0.01 & 0.03 \\
Years of Education & 8.28 & 8.14 \\
Food Voucher Recipient & 0.50 & 0.58 \\
Currently Married & 0.10 & 0.14 \\
Ever Married & 0.13 & 0.16 \\
\hline Hotelling's T-Squared Test & F-Statistic: & 1.0476 \\
& P-Value: & 0.4232 \\
\hline
\end{tabular}

Notes: Means of demographic covariates are presented for those with CD4 counts below the thresholds (150 cells $/ \mu \mathrm{L}<\mathrm{X}<200$ cells $/ \mu \mathrm{L})$ and above the threshold $(200$ cells $/ \mu \mathrm{L}<\mathrm{X}<250$ cells $/ \mu \mathrm{L})$. We performed a Hotelling's T-squared test to examine the joint balance of covariate means between the groups. The null hypothesis is statistical balance in means over the threshold. We fail to reject the null hypothesis at the $95 \%$ level of significance. 
Table 3: Robustness Checks on Causal Estimates Over Bandwidths

Regression Discontinuity Bandwidths for Outcome Measure 1: Probability that the Surveyed Adult Missed a Meal for Financial Reasons

\begin{tabular}{|c|c|c|c|c|c|c|}
\hline \multirow{3}{*}{ Treatment Effect at $<1$ Year } & 50 & 100 & 200 & 300 & 400 & Full Sample \\
\hline & 0.0482 & $0.102 * * *$ & $0.117 * * *$ & $0.106 * * *$ & $0.103 * * *$ & $0.0974 * * *$ \\
\hline & {$[-0.0326,0.129]$} & {$[0.0388,0.166]$} & {$[0.0730,0.162]$} & {$[0.0706,0.142]$} & {$[0.0718,0.135]$} & {$[0.0663,0.128]$} \\
\hline \multirow[t]{2}{*}{ Treatment Effect at 1 Year } & 0.0599 & $0.0938 * * *$ & $0.0859 * * *$ & $0.0715^{* * *}$ & $0.0730^{* * *}$ & $0.0666^{* * *}$ \\
\hline & {$[-0.0237,0.144]$} & {$[0.0353,0.152]$} & {$[0.0466,0.125]$} & {$[0.0412,0.102]$} & {$[0.0459,0.100]$} & {$[0.0405,0.0928]$} \\
\hline \multirow[t]{2}{*}{ Treatment Effect at 2 Years } & 0.0426 & 0.0330 & $0.0470 * * *$ & $0.0531 * * *$ & $0.0469 * * *$ & $0.0402 * * *$ \\
\hline & {$[-0.0217,0.107]$} & {$[-0.00948,0.0755]$} & {$[0.0167,0.0773]$} & {$[0.0273,0.0790]$} & {$[0.0241,0.0697]$} & {$[0.0177,0.0627]$} \\
\hline \multirow[t]{2}{*}{ Treatment Effect at 3 Years } & -0.0127 & 0.00694 & 0.0176 & $0.0330 * * *$ & $0.0372 * * *$ & $0.0309 * * *$ \\
\hline & {$[-0.0596,0.0341]$} & {$[-0.0234,0.0373]$} & {$[-0.00586,0.0412]$} & {$[0.0123,0.0536]$} & {$[0.0178,0.0565]$} & {$[0.0110,0.0508]$} \\
\hline \multirow[t]{2}{*}{ Treatment Effect at 4 Years } & -0.0139 & 0.000883 & 0.0163 & $0.0217 * *$ & $0.0196^{* *}$ & $0.0134 *$ \\
\hline & {$[-0.0587,0.0309]$} & {$[-0.0266,0.0283]$} & {$[-0.00456,0.0371]$} & {$[0.00434,0.0390]$} & {$[0.00374,0.0355]$} & {$[-0.00257,0.0294]$} \\
\hline \multirow{2}{*}{ Treatment Effect at 5 Years } & 0.00963 & 0.0131 & 0.0173 & $0.0207 * *$ & $0.0175^{* *}$ & 0.0113 \\
\hline & {$[-0.0440,0.0633]$} & {$[-0.0196,0.0458]$} & {$[-0.00504,0.0395]$} & {$[0.00310,0.0383]$} & {$[0.00187,0.0332]$} & {$[-0.00438,0.0270]$} \\
\hline \multirow[t]{2}{*}{ Treatment Effect at 6 Years } & -0.0246 & -0.00667 & 0.00418 & 0.00789 & 0.00496 & -0.000718 \\
\hline & {$[-0.0651,0.0158]$} & {$[-0.0337,0.0203]$} & {$[-0.0159,0.0243]$} & {$[-0.00774,0.0235]$} & {$[-0.00902,0.0189]$} & {$[-0.0147,0.0133]$} \\
\hline$N$ & 1621 & 3216 & 6188 & 8550 & 10503 & 12112 \\
\hline
\end{tabular}

Regression Discontinuity Bandwidths for Outcome Measure 2: Probability that Any Adult in the Household Missed a Meal for Financial Reasons

Treatment Effect at $<1$ Year

Treatment Effect at 1 Year

50

$0.0872 * \quad 0.152 * * *$

$[-0.0143,0.189]$

$0.132 * *$

[0.0208, 0.243]

0.0773 *

$[-0.00898,0.164]$

0.0147

[-0.0519, 0.0814]

0.00193

$[-0.0613,0.0652]$

0.0459

[-0.0307, 0.122]

$-0.0393$

[-0.0911, 0.0125]

1618
[0.0732, 0.231]

$0.151 * * *$

$[0.0759,0.226]$

$0.0788 * *$

$[0.0177,0.140]$

$0.0492 * *$

[0.00126, 0.0972]

0.0163

$[-0.0255,0.0581]$

0.0377

$[-0.0115,0.0868]$

$-0.0153$

$[-0.0507,0.0200]$

3211
Regression Discontinuity Bandwidths for Outcome Measure 3: Probability that Any Child in the Household Missed a Meal for Financial Reasons

Treatment Effect at $<1$ Year

Treatment Effect at 1 Year

Treatment Effect at 2 Years

Treatment Effect at 3 Years

Treatment Effect at 4 Years

Treatment Effect at 5 Years

Treatment Effect at 6 Years

\begin{tabular}{ll}
\multicolumn{1}{c}{50} & \multicolumn{1}{c}{100} \\
\hline 0.0496 & $0.0898 * * *$ \\
{$[-0.0233,0.122]$} & {$[0.0317,0.148]$} \\
0.0549 & $0.0777 * * *$ \\
{$[-0.0180,0.128]$} & {$[0.0257,0.130]$} \\
0.0228 & 0.0219 \\
{$[-0.0236,0.0692]$} & {$[-0.0110,0.0549]$} \\
-0.00825 & 0.00572 \\
{$[-0.0495,0.0330]$} & {$[-0.0207,0.0321]$} \\
-0.00638 & 0.00141 \\
{$[-0.0454,0.0327]$} & {$[-0.0224,0.0252]$} \\
-0.00818 & 0.000524 \\
{$[-0.0488,0.0324]$} & {$[-0.0245,0.0255]$} \\
-0.0220 & -0.00919 \\
{$[-0.0572,0.0131]$} & {$[-0.0323,0.0139]$} \\
1617 & 3209
\end{tabular}

\begin{tabular}{ll}
\multicolumn{1}{c}{200} & \multicolumn{1}{c}{300} \\
\hline $0.103 * * *$ & $0.0885 * * *$ \\
{$[0.0627,0.143]$} & {$[0.0567,0.120]$} \\
$0.0786 * * *$ & $0.0598^{*} * *$ \\
{$[0.0424,0.115]$} & {$[0.0324,0.0873]$} \\
$0.0305 * *$ & $0.0356 * * *$ \\
{$[0.00728,0.0538]$} & {$[0.0157,0.0555]$} \\
0.0113 & $0.0224 * *$ \\
{$[-0.00812,0.0307]$} & {$[0.00520,0.0396]$} \\
0.0151 & $0.0189 * *$ \\
{$[-0.00300,0.0332]$} & {$[0.00371,0.0341]$} \\
0.00907 & $0.0152 * *$ \\
{$[-0.00845,0.0266]$} & {$[0.000991,0.0295]$} \\
-0.000226 & 0.00523 \\
{$[-0.0162,0.0157]$} & {$[-0.00765,0.0181]$} \\
6181 & 8540
\end{tabular}

\begin{tabular}{l}
\multicolumn{1}{c}{400} \\
$0.0883 * * *$ \\
{$[0.0598,0.117]$} \\
$0.0546 * * *$ \\
{$[0.0306,0.0786]$} \\
$0.0301 * * *$ \\
{$[0.0120,0.0482]$} \\
$0.0217 * * *$ \\
{$[0.00559,0.0379]$} \\
$0.0133 *$ \\
{$[-0.000537,0.0271]$} \\
0.0108 \\
{$[-0.00239,0.0241]$} \\
0.000810 \\
{$[-0.0111,0.0127]$} \\
10493
\end{tabular}

Full Sample

$0.0827 * * *$

$[0.0549,0.110]$

$0.0491 * * *$

[0.0264, 0.0717]

$0.0243 * * *$

$[0.00672,0.0418]$

$0.0164 * *$

[0.000243, 0.0325]

0.00794

[-0.00532, 0.0212]

0.00556

$[-0.00719,0.0183]$

$-0.00384$

[-0.0152, 0.00747] 12102

$* \mathrm{p}<0.1, * * \mathrm{p}<0.05, * * * \mathrm{p}<0.01$

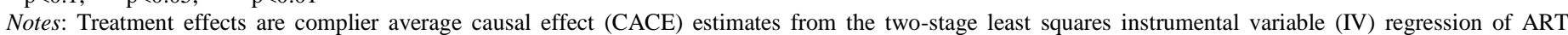

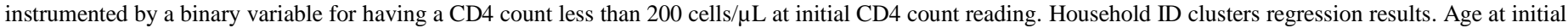

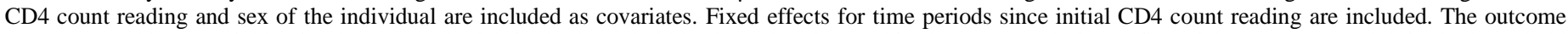

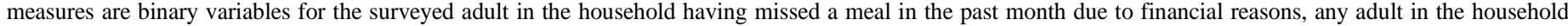

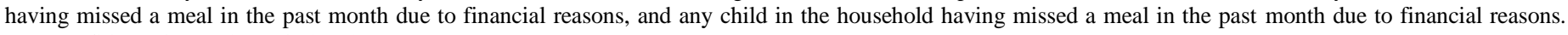
$95 \%$ confidence intervals are in brackets. 
Table 4: Robustness Checks on Threshold Assignment

\begin{tabular}{|c|c|c|c|c|}
\hline \multirow[b]{3}{*}{ False Treatment Effect at $<1$ Year } & \multicolumn{4}{|c|}{$\begin{array}{c}\text { False CD4 Count Threshold (cells/ } \mu \mathrm{L} \text { ) for Outcome Measure 1: Probability } \\
\text { that the Surveyed Adult Missed a Meal for Financial Reasons }\end{array}$} \\
\hline & 100 & 300 & 400 & 500 \\
\hline & $\begin{array}{l}-1.030 \\
{[-5.190,3.131]}\end{array}$ & $\begin{array}{l}-0.0898 \\
{[-0.455,0.275]}\end{array}$ & $\begin{array}{l}-1.207 \\
{[-22.65,20.24]}\end{array}$ & $\begin{array}{l}-0.226 \\
{[-3.723,3.271]}\end{array}$ \\
\hline False Treatment Effect at 1 Year & $\begin{array}{l}-0.574 \\
{[-2.785,1.637]}\end{array}$ & $\begin{array}{l}0.270 \\
{[-0.119,0.660]}\end{array}$ & $\begin{array}{l}-1.735 \\
{[-21.30,17.83]}\end{array}$ & $\begin{array}{l}1.291 \\
{[-3.899,6.481]}\end{array}$ \\
\hline False Treatment Effect at 2 Years & $\begin{array}{l}-0.880 \\
{[-6.926,5.165]}\end{array}$ & $\begin{array}{l}0.315 \\
{[-0.104,0.734]}\end{array}$ & $\begin{array}{l}-3.310 \\
{[-42.74,36.12]}\end{array}$ & $\begin{array}{l}1.874 \\
{[-9.344,13.09]}\end{array}$ \\
\hline False Treatment Effect at 3 Years & $\begin{array}{l}0.146 \\
{[-2.472,2.763]}\end{array}$ & $\begin{array}{l}0.0831 \\
{[-0.290,0.457]}\end{array}$ & $\begin{array}{l}-2.994 \\
{[-37.12,31.13]}\end{array}$ & $\begin{array}{l}4.508 \\
{[-20.54,29.55]}\end{array}$ \\
\hline False Treatment Effect at 4 Years & $\begin{array}{l}-0.278 \\
{[-2.546,1.990]}\end{array}$ & 0.216 -0.108,0.540] & $\begin{array}{l}-3.347 \\
{[-44.44,37.75]}\end{array}$ & $\begin{array}{l}1.778 \\
{[-1.904,5.460]}\end{array}$ \\
\hline False Treatment Effect at 5 Years & $\begin{array}{l}-0.506 \\
{[-3.978,2.965]}\end{array}$ & $\begin{array}{l}0.0606 \\
{[-0.305,0.426]}\end{array}$ & $\begin{array}{l}-2.065 \\
{[-33.81,29.69]}\end{array}$ & $\begin{array}{l}1.296 \\
{[-7.276,9.868]}\end{array}$ \\
\hline False Treatment Effect at 6 Years & 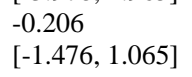 & 0.149 & -9.260 & 0.525 -3.850,4.899] \\
\hline \multirow[t]{2}{*}{$N$} & 6678 & 3780 & 2247 & 1198 \\
\hline & \multicolumn{4}{|c|}{$\begin{array}{l}\text { False CD4 Count Threshold (cells/ } \mu \mathrm{L}) \text { for Outcome Measure 2: Probability } \\
\text { that Any Adult in the Household Missed a Meal for Financial Reasons }\end{array}$} \\
\hline False Treatment Effect at $<1$ Year & $\begin{array}{l}-0.891 \\
{[-9.105,7.323]}\end{array}$ & $\begin{array}{l}0.0888 \\
{[-0.426,0.603]}\end{array}$ & $\begin{array}{l}-1.092 \\
{[-21.56,19.37]}\end{array}$ & $\begin{array}{l}-0.123 \\
{[-3.487,3.242]}\end{array}$ \\
\hline False Treatment Effect at 1 Year & $\begin{array}{l}-1.052 \\
{[-5.589,3.484]}\end{array}$ & $\begin{array}{l}0.428 \\
{[-0.124,0.981]}\end{array}$ & $\begin{array}{l}-1.660 \\
{[-20.34,17.02]}\end{array}$ & $\begin{array}{l}2.296 \\
{[-5.303,9.895]}\end{array}$ \\
\hline False Treatment Effect at 2 Years & $\begin{array}{l}-1.392 \\
{[-13.95,11.16]}\end{array}$ & $\begin{array}{l}0.309 \\
{[-0.305,0.924]}\end{array}$ & $\begin{array}{l}-3.179 \\
{[-40.79,34.43]}\end{array}$ & $\begin{array}{l}0.225 \\
{[-8.266,8.716]}\end{array}$ \\
\hline False Treatment Effect at 3 Years & $\begin{array}{l}-0.382 \\
{[-6.135,5.371]}\end{array}$ & $\begin{array}{l}0.143 \\
{[-0.383,0.669]}\end{array}$ & $\begin{array}{l}-2.698 \\
{[-35.18,29.78]}\end{array}$ & $\begin{array}{l}3.455 \\
{[-19.12,26.03]}\end{array}$ \\
\hline False Treatment Effect at 4 Years & $\begin{array}{l}-0.638 \\
{[-5.402,4.126]}\end{array}$ & $\begin{array}{l}0.289 \\
{[-0.165,0.744]}\end{array}$ & $\begin{array}{l}-3.187 \\
{[-42.38,36.01]}\end{array}$ & $\begin{array}{l}1.038 \\
{[-2.447,4.523]}\end{array}$ \\
\hline False Treatment Effect at 5 Years & $\begin{array}{l}-1.313 \\
{[-8.829,6.202]}\end{array}$ & $\begin{array}{l}0.210 \\
{[-0.298,0.719]}\end{array}$ & $\begin{array}{l}-2.150 \\
{[-32.49,28.19]}\end{array}$ & $\begin{array}{l}2.694 \\
{[-14.56,19.95]}\end{array}$ \\
\hline False Treatment Effect at 6 Years & $\begin{array}{l}-0.438 \\
{[-3.120,2.245]}\end{array}$ & $\begin{array}{l}0.251 \\
{[-0.235,0.737]}\end{array}$ & $\begin{array}{l}-8.997 \\
{[-137.9,119.9]}\end{array}$ & $\begin{array}{l}-0.00820 \\
{[-3.099,3.082]}\end{array}$ \\
\hline \multirow[t]{2}{*}{$N$} & 6668 & 3777 & 2247 & 1198 \\
\hline & \multicolumn{4}{|c|}{$\begin{array}{l}\text { False CD4 Count Threshold (cells/ } \mu \mathrm{L}) \text { for Outcome Measure 3: Probability } \\
\text { that Any Child in the Household Missed a Meal for Financial Reasons }\end{array}$} \\
\hline False Treatment Effect at $<1$ Year & $\begin{array}{l}-0.937 \\
{[-5.551,3.676]}\end{array}$ & $\begin{array}{l}-0.264 * \\
{[-0.558,0.0296]}\end{array}$ & $\begin{array}{l}-0.699 \\
{[-14.75,13.35]}\end{array}$ & $\begin{array}{l}-0.374 \\
{[-2.656,1.908]}\end{array}$ \\
\hline False Treatment Effect at 1 Year & $\begin{array}{l}-0.810 \\
{[-3.354,1.734]}\end{array}$ & $\begin{array}{l}0.255 \\
{[-0.0667,0.576]}\end{array}$ & $\begin{array}{l}-1.285 \\
{[-14.15,11.58]}\end{array}$ & $\begin{array}{l}1.349 \\
{[-3.745,6.443]}\end{array}$ \\
\hline False Treatment Effect at 2 Years & $\begin{array}{l}-0.843 \\
{[-7.241,5.556]}\end{array}$ & $\begin{array}{l}0.149 \\
{[-0.217,0.516]}\end{array}$ & $\begin{array}{l}-2.362 \\
{[-28.33,23.61]}\end{array}$ & $\begin{array}{l}-0.182 \\
{[-6.852,6.488]}\end{array}$ \\
\hline False Treatment Effect at 3 Years & $\begin{array}{l}-0.120 \\
{[-3.091,2.851]}\end{array}$ & $\begin{array}{l}0.0297 \\
{[-0.268,0.327]}\end{array}$ & $\begin{array}{l}-1.778 \\
{[-24.09,20.53]}\end{array}$ & $\begin{array}{l}1.084 \\
{[-7.813,9.981]}\end{array}$ \\
\hline False Treatment Effect at 4 Years & $\begin{array}{l}-0.364 \\
{[-2.869,2.141]}\end{array}$ & $\begin{array}{l}0.123 \\
{[-0.142,0.389]}\end{array}$ & $\begin{array}{l}-2.197 \\
{[-29.17,24.78]}\end{array}$ & $\begin{array}{l}1.253 \\
{[-1.909,4.414]}\end{array}$ \\
\hline False Treatment Effect at 5 Years & $\begin{array}{l}-0.442 \\
{[-4.151,3.267]}\end{array}$ & $\begin{array}{l}-0.0211 \\
{[-0.315,0.273]}\end{array}$ & $\begin{array}{l}-1.301 \\
{[-22.11,19.50]}\end{array}$ & $\begin{array}{l}2.033 \\
{[-11.19,15.26]}\end{array}$ \\
\hline False Treatment Effect at 6 Years & $\begin{array}{l}-0.206 \\
{[-1.596,1.184]}\end{array}$ & $\begin{array}{l}0.0454 \\
{[-0.232,0.323]}\end{array}$ & $\begin{array}{l}-5.984 \\
{[-94.33,82.36]}\end{array}$ & $\begin{array}{l}0.249 \\
{[-2.263,2.760]}\end{array}$ \\
\hline$N$ & 6671 & 3777 & 2247 & 1198 \\
\hline
\end{tabular}

Notes: Treatment effects are complier average causal effect (CACE) estimates from the two-stage least squares instrumental variable (IV) regressions of ART instrumented by having a CD4 count less than the listed false cells/ $\mu \mathrm{L}$ threshold at initial CD4 count reading. Regression results are clustered by household. Age at initial CD4 count reading and sex of the individual are included as covariates. Fixed effects for time periods since initial CD4 count reading are also included. Outcome measures are binary variables for the surveyed adult in the household having missed a meal in the past month due to financial reasons, any adult in the household having missed a meal in the past month due to financial reasons, and any child in the household having missed a meal in the past month due to financial reasons. $95 \%$ confidence intervals are in brackets 